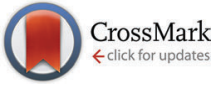

Cite this: Phys. Chem. Chem. Phys., 2014, 16, 26798

\section{The effect of the cation alkyl chain length on density and diffusion in dialkylpyrrolidinium bis(mandelato)borate ionic liquids $\dagger$}

\author{
Andrei Filippov, ${ }^{\star a b}$ Mamoun Taher, ${ }^{a}$ Faiz Ullah Shah, ${ }^{a}$ Sergei Glavatskih ${ }^{c d}$ and \\ Oleg N. Antzutkin ${ }^{\text {ae }}$
}

\begin{abstract}
The physicochemical properties of ionic liquids are strongly affected by the selective combination of the cations and anions comprising the ionic liquid. In particular, the length of the alkyl chains of ions has a clear influence on the ionic liquid's performance. In this paper, we study the self-diffusion of ions in a series of halogen-free boron-based ionic liquids (hf-BILs) containing bis(mandelato)borate anions and dialkylpyrrolidinium cations with long alkyl chains $\mathrm{C}_{n} \mathrm{H}_{2 n+1}$ with $n$ from 4 to 14 within a temperature range of 293-373 K. It was found that the hf-BILs with $n=4-7$ have very similar diffusion coefficients, while hf-BILs with $n=10-14$ exhibit two liquid sub-phases in almost the entire temperature range studied (293-353 K). Both liquid sub-phases differ in their diffusion coefficients, while values of the slower diffusion coefficients are close to those of hf-BILs with shorter alkyl chains. To explain the particular dependence of diffusion on the alkyl chain length, we examined the densities of the hf-BILs studied here. It was shown that the dependence of the density on the number of $\mathrm{CH}_{2}$ groups in long alkyl chains of cations can be accurately described using a "mosaic type" model, where regions of long alkyl chains of cations (named 'aliphatic' regions) and the residual chemical moieties in both cations and anions (named 'ionic' regions) give additive contributions. Changes in density due to an increase in temperature and the number of $\mathrm{CH}_{2}$ groups in the long alkyl chains of cations are determined predominantly by changes in the free volume of the 'ionic' regions, while 'aliphatic' regions are already highly compressed by van der Waals forces, which results in only infinitesimal changes in their free volumes with temperature.
\end{abstract}

Received 5th September 2014, Accepted 27th October 2014

DOI: $10.1039 / c 4 c p 03996 c$

www.rsc.org/pccp
The physicochemical properties of ILs are strongly affected by the selective combination of cations and anions. In particular, the length of the alkyl chains in the ions has an obvious influence on the IL's performance. ${ }^{11,12}$ Local mobility and translational motion (diffusion) are the key phenomena for understanding molecular mechanisms of many industrial processes in which ILs are involved. Numerous methods can be used to study molecular mobility; however, NMR is an exceptionally informative technique for analysing local molecular motion and translational diffusion coefficients. The application of NMR to examine IL diffusion has been demonstrated in a number of previous studies, where proton pulsed field gradient $\left({ }^{1} \mathrm{H}\right.$ PFG) spin-echo and stimulated echo were used. $^{13-19}$ It has also been shown by NMR that ionic liquids may spontaneously form two microscopically intercalated liquid sub-phases, in which ionic species have different diffusion coefficients. ${ }^{17,19}$ Density is also a very important property of ILs that must be considered in design problems of chemical engineering and materials science. Densities of ionic liquids have been thoroughly studied in a number of experimental and theoretical studies. ${ }^{20-25}$ In particular, Paduszynski and Domanska, ${ }^{22}$ Lazzus, $^{25}$ Slattery et al. $^{21}$ and Rebelo et $a .^{20}$ 
have explored the dependence of density of various types of ionic liquids on the presence and the structure of different functional groups in cations and anions of ILs. The molecular diffusion and density of the substance are two inter-related properties that, alongside other properties, are related to the substance's structure on a molecular scale.

The objective of this work is to explore the self-diffusion of novel halogen-free boron-containing ILs (hf-BILs) with pyrrolidinium cations having alkyl groups of different chain lengths, ${ }^{26}$ and to relate this self-diffusion to molecular-scale properties of the hf-BILs obtained from the density analysis. hf-BILs were selected for this study, because of their outstanding lubrication performance in ferrous and non-ferrous material contacts. ${ }^{8,26}$ Recently, a growing interest has been emerged in hf-BILs containing orthoborate anions combined with a variety of cations such as phosphonium, cholinium, pyrrolidinium, imidazolium and ammonium. ${ }^{7,10,26-28}$ These hf-BILs are halogen-free, hydrophobic and hydrolytically stable. On the other hand, most of the ILs, widely studied to date in tribological applications, contain halogenated anions such as tetrafluoroborate $\left[\mathrm{BF}_{4}{ }^{-}\right]$, hexafluorophosphate $\left[\mathrm{PF}_{6}{ }^{-}\right]$, tris(tetrafluoroethyl)trifluorophosphate, $\left[\mathrm{FAP}^{-}\right]$, bis(trifluoromethylsulfonyl)amide, $\left[\mathrm{TFSA}^{-}\right]$(or $\left[\mathrm{Ntf}_{2}^{-}\right]$), etc. In the course of rubbing, or/and when exposed to harsh conditions (for example, under UV/X-ray/electron irradiation in a vacuum) halogen containing ILs may release toxic and corrosive hydrogen halides to the surrounding environment. Therefore, replacing $\left[\mathrm{BF}_{4}^{-}\right],\left[\mathrm{PF}_{6}^{-}\right],\left[\mathrm{FAP}^{-}\right],\left[\mathrm{TFSA}^{-}\right]$and other currently widely used halogen containing anions with more hydrophobic halogen-free anions, such as orthoborate anions, is one of possible ways to avoid corrosion and toxicity of IL-based lubricants, in particular, during their exploitation under harsh or extreme conditions, such as in ultra-high vacuum space applications. In this study, hf-BILs with the bis(mandelato)borate anion, $\left[\mathrm{BMB}^{-}\right],{ }^{7,29}$ and dialkylpyrrolidinium cations having alkyl chains, $\mathrm{C}_{n} \mathrm{H}_{2 n+1}$, with $n$ from 4 to 14 were employed.

\section{Experimental section}

\subsection{Synthesis}

Pyrrolidinium bis(mandelato)borate hf-BILs ([C $\mathrm{C}_{n} \mathrm{C}_{1}$ Pyrr $][\mathrm{BMB}]$, $n=4,5,6,7,8,10$ and 14) (see Fig. 1) were synthesised as described by $\mathrm{Yu}$ et al. ${ }^{29}$ Shah et al., ${ }^{10}$ and Taher et $a .^{26}$ The chemical structure and purity of the synthesised hf-BILs were characterised by multinuclear $\left({ }^{1} \mathrm{H},{ }^{13} \mathrm{C}\right.$, and $\left.{ }^{11} \mathrm{~B}\right)$ NMR spectroscopy. The data obtained confirmed the structure and purity of all synthesised hf-BILs. Before experiments the ILs were

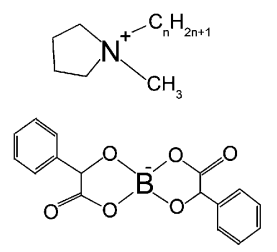

Fig. 1 lonic components of the studied ionic liquids. The dialkylpyrrolidinium cation (top) and the bis(mandelato)borate anion (bottom). de-gassed under vacuum (under a pressure of less than $10^{-3} \mathrm{mbar}$ ) as thin layers at $110{ }^{\circ} \mathrm{C}$ for $\mathrm{ca}$. three hours to remove traces of solvents and water.

\subsection{Diffusion measurements}

Three hundred $\mu \mathrm{l}$ of the IL was placed in a glass tube with a $5 \mathrm{~mm}$ internal diameter, and the tube was flame-sealed to prevent both leakage and any further contact with air. NMR spectra of hf-BILs were recorded on an Agilent/Varian/Chemagnetics InfinityPlus CMX-360 $\left(B_{0}=8.46 \mathrm{~T}\right)$ spectrometer. For ${ }^{1} \mathrm{H}$ NMR diffusion measurements, the standard stimulated echo pulse sequence was applied. ${ }^{30}$ In this case, the diffusion decay (DD) of the echo amplitude, $A\left(2 \tau, \tau_{1}, g, \delta\right)$, can be described by the following equation, eqn (1):

$$
A\left(2 \tau, \tau_{1}, g, \delta\right)=\frac{I}{2} \exp \left(-\frac{2 \tau}{T_{2}}-\frac{\tau_{1}}{T_{1}}\right) \exp \left(-\gamma^{2} \delta^{2} g^{2} D t_{\mathrm{d}}\right)
$$

where $I$ is the factor proportional to the proton content; $T_{1}$ and $T_{2}$ are times of the spin-lattice and the spin-spin relaxation, respectively; $\tau_{1}$ and $\tau$ are time intervals between the first and second, and the second and third radio frequency pulses; $t_{\mathrm{d}}=(\Delta-\delta / 3)$ is the diffusion time, $\Delta$ the time delay between two identical gradient pulses; and $D$ is the diffusion coefficient. The amplitude of the pulsed field gradient was set to a constant $\left(g=1.15 \mathrm{~T} \mathrm{~m}^{-1}\right)$ and $\Delta$ was kept at $100 \mathrm{~ms}$. The duration of the gradient pulse, $\delta$, was varied stepwise from 0.5 to $7.7 \mathrm{~ms}$ with a $0.04 \mathrm{~ms}$ time interval. The majority of the experiments were performed with $\tau=11 \mathrm{~ms}$ and $\tau_{1}=100 \mathrm{~ms}$. The number of accumulated signal transients was varied between 16 and 320 to achieve desirable uncertainty in $D$ not larger than $10 \%$.

\subsection{Density}

An Anton-Paar DMA 4100M density meter was used to measure sample density in the temperature range from 293 to $353 \mathrm{~K}$ as described by Taher et al. ${ }^{26}$

\section{Results}

\subsection{Diffusion}

The sample was heated stepwise by 10 degrees, allowed to reach thermal equilibrium for 15 minutes, and then the PFGstimulated echo run was started, which took about 30 minutes. For hf-BILs in the range of $n$ from 4 to 8 , no echo signal was observed until the temperature reached $333 \mathrm{~K}$, because of the fast $T_{2}$ NMR relaxation rates of protons of both ions. At $333 \mathrm{~K}$ and higher temperatures, diffusion measurements were taken and DDs were obtained. These DDs were single-exponential (eqn (1)), therefore, providing a single $D$ for these ILs at each temperature. Exact values of $D$ s for $\left[\mathrm{C}_{n} \mathrm{C}_{1}\right.$ Pyrr $][\mathrm{BMB}]$ hf-BILs are presented in Table $\mathrm{S} 1$ of the ESI. $\dagger$ Temperature dependencies of $D$ s in Arrhenius plots for the samples with $n=4-8$ are shown in Fig. 2 by solid symbols. From this figure, one can see that $D$ s for samples with $n=4-7$ are close to one another, while $D$ s for $\left[\mathrm{C}_{8} \mathrm{C}_{1} \mathrm{Pyrr}\right][\mathrm{BMB}]$ are a factor of up to 1.5 higher. All of these $D$ s follow the temperature dependence, which is close to that of the Arrhenius type (shown by a dotted line). 


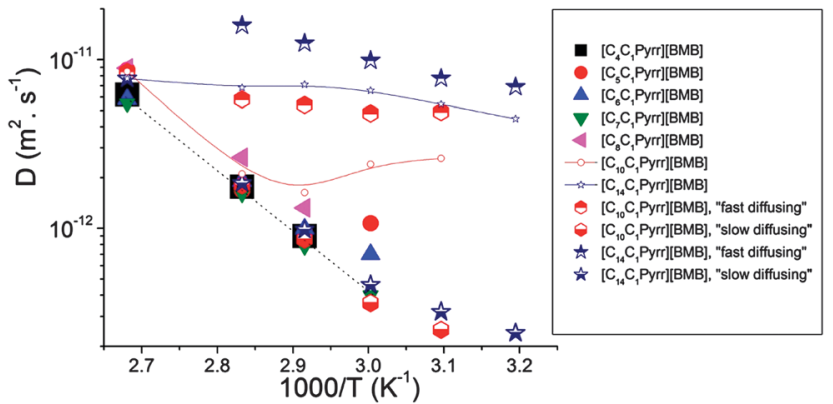

Fig. 2 Mean diffusion coefficients of $\left[\mathrm{C}_{n} \mathrm{C}_{1}\right.$ Pyrr] $[\mathrm{BMB}]$. Large filled symbols correspond to samples demonstrating single-component DDs $(n=4-8)$, while small open symbols with solid lines correspond to samples with more complex DDs ( $n=10$ and 14). Fractional diffusion coefficients for samples with $n=10$ and 14 obtained after CORE analysis ${ }^{31}$ of the corresponding diffusion decays shown by half-filled symbols. The dotted line shows the Arrhenius approximation for the temperature dependence of $D$ s of samples with single-exponential diffusion and 'slow diffusing' components.

For IL samples with $n=10$ and 14, stimulated echoes were observable at lower temperatures, 318 and $298 \mathrm{~K}$, respectively. However, DDs were definitely complex; therefore they were characterised, as a first approach, by the values of apparent (mean) Ds, which were estimated as derivatives of the corresponding DDs when the parameter " $\gamma^{2} g^{2} \delta^{2} t_{\mathrm{d}}$ " approaches zero (see eqn (2)):

$$
\bar{D}=\left.\frac{-\partial A\left(\gamma g \delta t_{\mathrm{d}} D\right)}{\partial\left(\gamma^{2} g^{2} \delta^{2} t_{\mathrm{d}}\right)}\right|_{\left(\gamma^{2} g^{2} \delta^{2} t_{\mathrm{d}}\right) \rightarrow 0}
$$

Fig. 2 shows the mean values of $D$ s for $\left[\mathrm{C}_{10} \mathrm{C}_{1} \mathrm{Pyrr}\right][\mathrm{BMB}]$ and $\left[\mathrm{C}_{14} \mathrm{C}_{1} \mathrm{Pyrr}\right][\mathrm{BMB}]$ (open symbols with connecting solid lines). Generally, $D$ s increase as the length of one alkyl substitute in the $\left[\mathrm{C}_{n} \mathrm{C}_{1} \text { Pyrr }\right]^{+}$cation $(n)$ increases. Note also that temperature dependencies of $D$ s became non-Arrhenius for $n=10$ and 14 .

The multi-componential form of a DD means that molecules contained in liquid diffuse with two or more Ds. For this reason, experimental diffusion decays for $n=10$ and 14 were examined using the CORE method for global analysis of the entire data set. ${ }^{31}$ Two diffusion components were detected for these hf-BILs at temperatures below $353 \mathrm{~K}$. The reliability of this decomposition was verified by the 'zero-level line' obtained after subtraction of the separated components from the original decay. Thus, DDs for $\left[\mathrm{C}_{n} \mathrm{C}_{1} \mathrm{Pyrr}\right][\mathrm{BMB}]$ with $n=10$ and 14 can be presented in the following form, eqn (3):

$$
A(\delta) / A(0)=P_{1} \exp \left(-\gamma^{2} \delta^{2} g^{2} D_{1} t_{\mathrm{d}}\right)+P_{2} \exp \left(-\gamma^{2} \delta^{2} g^{2} D_{2} t_{\mathrm{d}}\right)
$$

Here, $P_{i}$ and $D_{i}$ are apparent fractions and $D$ s associated with two diffusing species, respectively. The form of eqn (3) means that at least two molecular/ionic (or supra-molecular) species have different $D$ s at these temperatures. These species were termed here as "fast diffusing" and "slow diffusing". Fig. 2 (half-filled symbols) illustrates Arrhenius plots for temperature dependencies of fractional and apparent $D$ s obtained after CORE analysis of $\left[\mathrm{C}_{10} \mathrm{C}_{1} \mathrm{Pyrr}\right][\mathrm{BMB}]$ and $\left[\mathrm{C}_{14} \mathrm{C}_{1} \mathrm{Pyrr}\right][\mathrm{BMB}]$. From this figure, one can see that the "slow diffusing" component

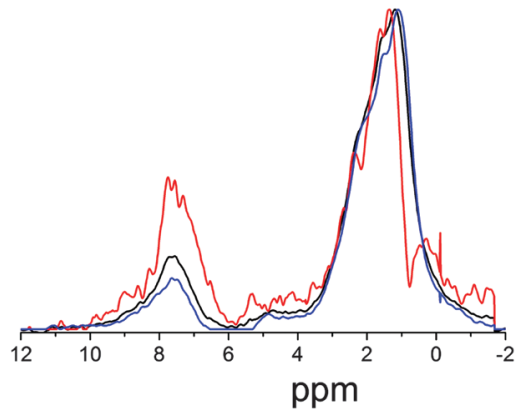

Fig. $3{ }^{1} \mathrm{H}$ NMR spectra of $\left[\mathrm{C}_{10} \mathrm{C}_{1}\right.$ Pyrr][BMB]: total (black), 'fast diffusing' (red) and 'slow diffusing' (blue) fractional components obtained after CORE decomposition of DDs. $T=343 \mathrm{~K}$. All spectra are normalised to the intensity of the aliphatic (at ca. $1.5 \mathrm{ppm}$ ) ${ }^{1} \mathrm{H}$ NMR signal.

coincides with (or is close to) Ds obtained for samples of $\left[\mathrm{C}_{n} \mathrm{C}_{1}\right.$ Pyrr $][\mathrm{BMB}]$ with $n=4-8$, while the "fast diffusing" species have a factor of 4-30 larger $D$ s. Data for $D$ s obtained after the CORE analysis are tabulated in Table S1 of the ESI. $\dagger$

In order to estimate the contributions of the anion and cation in the two different diffusing components, we performed ${ }^{1} \mathrm{H}$ NMR spectral analysis. Fig. 3 shows the shapes of measured and fractional (obtained by CORE) ${ }^{1} \mathrm{H}$ spectra of $\left[\mathrm{C}_{10} \mathrm{C}_{1}\right.$ Pyrr $][\mathrm{BMB}]$. Generally, the ${ }^{1} \mathrm{H}$ NMR spectrum of $\left[\mathrm{C}_{n} \mathrm{C}_{1}\right.$ Pyrr $][\mathrm{BMB}]$ contains signals of the $\left[\mathrm{C}_{n} \mathrm{C}_{1} \text { Pyrr }\right]^{+}$cation, in which mainly aliphatic $\mathrm{CH}_{2}$ protons (at ca. $1.3 \mathrm{ppm}$ ) are detected, and signals of the [BMB] anion (mainly aromatic protons at ca. $7.3 \mathrm{ppm}$ are observed). ${ }^{26}$ In Fig. 3, both fractional components contain signals from aliphatic and aromatic protons. From the figure, one can also see that the 'fast diffusing' component (red line) has a more intense NMR signal at chemical shifts of aromatic protons (at ca. $7.3 \mathrm{ppm}$ ), while the 'slow diffusing' (blue line) component has also the resonance line assigned to aromatic protons, but with a half the intensity of the red line. Of course, the intensities of both regions of the chemical shift are likely decreased to a different degree, because of NMR $T_{2}$ and $T_{1}$ relaxation processes. However, the trend is evident.

At temperatures higher than $353 \mathrm{~K}$, only one $D$ (common for both anions and cations) was observed in $\left[\mathrm{C}_{10} \mathrm{C}_{1} \mathrm{Pyrr}\right][\mathrm{BMB}]$ and $\left[\mathrm{C}_{14} \mathrm{C}_{1}\right.$ Pyrr $][\mathrm{BMB}]$ (see Fig. 2), meaning that the two sub-phases merged into one liquid phase, where the anions and cations diffuse at almost equal rates. Note that molecular weights of $\left[\mathrm{C}_{n} \mathrm{C}_{1} \mathrm{Pyrr}\right]^{+}\left(M_{\mathrm{w}}=100+14(n-1)\right.$, i.e. 226 and $282 \mathrm{~g} \mathrm{~mol}^{-1}$ for $n=10$ and 14 , respectively) and $[\mathrm{BMB}]^{-}\left(M_{\mathrm{w}}=311 \mathrm{~g} \mathrm{~mol}^{-1}\right)$ are comparable.

Arrhenius dependencies of $D$ s allow one to estimate activation energies (apparent activation energies) for diffusion. The Arrhenius type equation for diffusion has the form, see eqn (4):

$$
D=D_{0} \exp \left(-\frac{E_{\mathrm{D}}}{R T}\right)
$$

Here, $D_{0}$ is the pre-exponential factor independent of temperature, $E_{\mathrm{D}}$ the activation energy for diffusion, $R$ the universal gas constant, and $R T$ the thermal energy. Using eqn (4), one can estimate the apparent activation energies for diffusion in hf-BILs with $n=4-8$ (approximated by the dashed straight line in Fig. 2) 
as $67 \mathrm{~kJ} \mathrm{~mol}^{-1}$. For hf-BILs with $n=10$ and 14, the increase in temperature may lead to a change in the sub-phase structures. However, because these temperature dependencies are linear in Arrhenius coordinates, we can also formally describe them by their apparent activation energies for diffusion. For the 'slow diffusing' component (approximated by the dashed straight line in Fig. 2), this gives the same activation energy for diffusion $\left(67 \mathrm{~kJ} \mathrm{~mol}^{-1}\right)$ as for $\left[\mathrm{C}_{n} \mathrm{C}_{1} \mathrm{Pyrr}\right][\mathrm{BMB}]$ with $n=4-8$; while for the linear parts of the temperature dependence for the 'fast diffusing' components of DDs, this analysis gives $9 \mathrm{~kJ} \mathrm{~mol}^{-1}$ for $\left[\mathrm{C}_{10} \mathrm{C}_{1}\right.$ Pyrr $][\mathrm{BMB}]$ and $22 \mathrm{~kJ} \mathrm{~mol}^{-1}$ for $\left[\mathrm{C}_{14} \mathrm{C}_{1} \mathrm{Pyrr}\right][\mathrm{BMB}]$.

Diffusion in the studied hf-BILs demonstrated some peculiarities. Indeed, (i) typically, an increase in the size of the molecules and an increase in the alkyl chain length of the hydrocarbon lead to a certain decrease in the diffusion coefficient. However, in our hf-BILs, the $D$ values did not change as $n$ increased and coincided with $D$ s of the 'slow diffusing' component. (ii) hf-BILs contain two types of ions; however, for $n=4-8$, only one diffusion coefficient was observed, while for $n=10-14$, two $D$ s were detected at $T<353 \mathrm{~K}$.

A pertinent question is whether different values of $D$ s correspond to different ions in $\left[\mathrm{C}_{n} \mathrm{C}_{1}\right.$ Pyrr $][\mathrm{BMB}]$. Indeed, bulkier cations (with a somewhat larger hydrodynamic radius, $R_{\mathrm{H}}$, because of a long alkyl chain) would probably diffuse more slowly than the $[\mathrm{BMB}]^{-}$anion. However, molecular weights $\left(M_{\mathrm{w}}\right)$ of the $[\mathrm{BMB}]^{-}$ anion $\left(311 \mathrm{~g} \mathrm{~mol}^{-1}\right.$ ) and $\left[\mathrm{C}_{n} \mathrm{C}_{1} \mathrm{Pyrr}\right]^{+}$cations (226 and $282 \mathrm{~g} \mathrm{~mol}^{-1}$ for $n=10$ and 14, respectively) do not differ much and, therefore, $R_{\mathrm{H}}$, for these cations and anions should be similar, taking into account a simplified relationship between $R_{\mathrm{H}}$ and $M_{\mathrm{W}}$ obtained from a simple geometrical consideration: $R_{\mathrm{H}} \sim\left(M_{\mathrm{w}}\right)^{1 / 3}$. Therefore, the observed large difference in $D$ s for the 'fast diffusing' and 'slow diffusing' components in $\left[\mathrm{C}_{n} \mathrm{C}_{1}\right.$ Pyrr $][\mathrm{BMB}]$ with $n=10$ and 14 cannot be attributed to the difference in sizes of cations and anions in these hf-BILs. In contrast, formation of supramolecular associations of cations stabilised by van der Waals interactions between long alkyl chains of pyrrolidinium cations may be invoked in explaining this type of effect.

The most common way to describe self-diffusion in a liquid is by applying the free-volume theory, ${ }^{32}$ which was demonstrated specifically on lipid systems containing long acyl chains. ${ }^{33}$ Free volume is a microscopic parameter of a sample, which controls the diffusion of molecules and the macroscopic bulk sample density. Therefore, the analysis of density in the studied hf-BILs, alongside other factors, might be helpful to explain the diffusion characteristics of hf-BILs.

\subsection{Density}

The dependence of hf-BIL density on the long alkyl chain length of pyrrolidinium cations is shown in Fig. 4 at different temperatures. These data were also tabulated by Taher et al. ${ }^{26}$ Uncertainty of the measured density values is within the uncertainty of the instrument used, $2 \times 10^{-5} \mathrm{~g} \mathrm{~cm}^{-3}$. Each presented density value is an average of five readings. One can see some relationship of the densities on the temperature and the cation long alkyl chain length. Firstly, the densities decrease as the temperature increases for all samples. This is typical for many substances

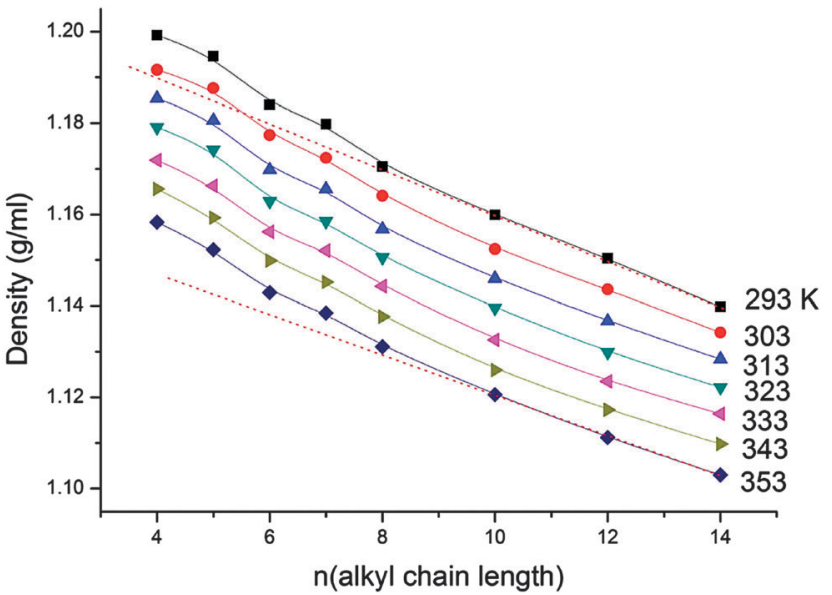

Fig. 4 Dependence of densities of the studied ionic liquids on the number, $n$, of $\mathrm{CH}_{2}$ and $\mathrm{CH}_{3}$ groups in the long alkyl chain of cations, $-\mathrm{C}_{n} \mathrm{H}_{2 n+1}$.

and can be explained by loose molecular packing (in this particular case, by different ions) at increased temperature, because of the gradual increase in local molecular mobility and molecular volumes.

The second peculiarity is the decrease in hf-BIL density as the length of the long alkyl chain of cations increases. A similar trend has been observed by Machanová et al. for densities in the homologous series of $N$-alkyl-triethylammonium bis-\{(trifluoromethyl)sulfonyl\}imide ILs $\left(\left[\mathrm{N}_{n 222}\right]\left[\mathrm{Ntf}_{2}\right]\right.$ with $\left.n=6-14\right) .^{23}$ Density trends in $\left[\mathrm{N}_{n 222}\right]\left[\mathrm{Ntf}_{2}\right]$ ILs obtained by Machanová et al. ${ }^{23}$ and in $\left[\mathrm{C}_{n} \mathrm{C}_{1} \mathrm{Pyrr}\right][\mathrm{BMB}]$ in this study are rather peculiar, because the chain length dependence for saturated hydrocarbons from hexane to dodecane changes in the opposite manner (see Fig. 5, open squares): an increase in the number of $\mathrm{CH}_{2}$ groups in saturated hydrocarbons leads to an increase in density, because of progressively tighter packing of the hydrocarbon chains under

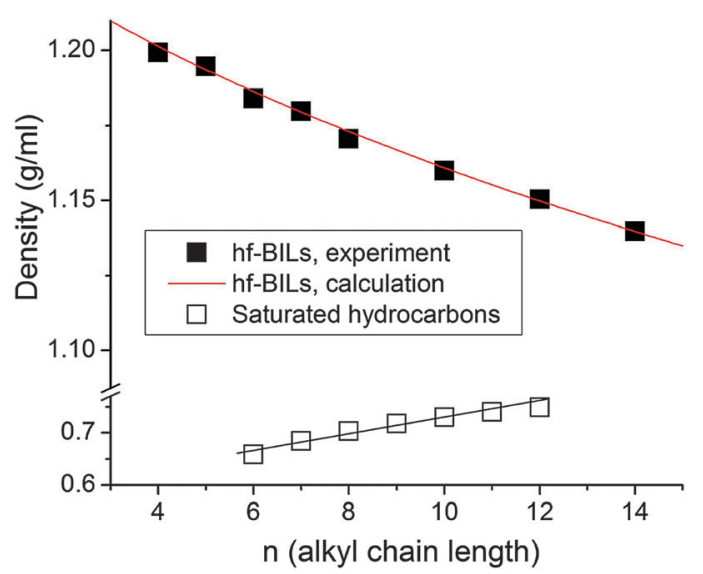

Fig. 5 Densities of studied ILs as a function of the number, $n$, of $\mathrm{CH}_{2}$ and $\mathrm{CH}_{3}$ groups in the long alkyl chains of cations, $-\mathrm{C}_{n} \mathrm{H}_{2 n+1}$, and a fit using eqn (5) with $m_{1}=1.08 \times 10^{-21} \mathrm{~g}, \rho_{\mathrm{I}}=1.24 \mathrm{~g} \mathrm{ml}^{-1}$ (from asymptotic extrapolation experimental trend to $n=0), V_{1}=m_{1} / \rho_{1}=8.78 \times 10^{-22} \mathrm{ml}$, $m_{\mathrm{CH}}=2.36 \times 10^{-23} \mathrm{~g}$, and $V_{\mathrm{CH}}$ was $2.6 \times 10^{-22} \mathrm{ml}$ (the best fitting parameter). Densities of saturated hydrocarbons, ${ }^{34} \mathrm{C}_{n} \mathrm{H}_{2 n+2}$, as a function of the number of $\mathrm{CH}_{2}$ and $\mathrm{CH}_{3}$ groups are shown for comparison. The temperature is $293 \mathrm{~K}$. 
van der Waals forces. From Fig. 5, one can also see that at room temperature the densities of the studied hf-BILs are larger than those of saturated hydrocarbons by a factor of $1.5-1.8$, meaning that regions of the hf-BILs (other than hydrocarbon chains) have larger densities, including the anion and a core part of the cation (without the long alkyl chain). Further below we will refer to the core regions of $\left[\mathrm{C}_{n} \mathrm{C}_{1}\right.$ Pyrr $][\mathrm{BMB}]$ ILs as 'ionic', while the cation long alkyl chain regions will be referred to as 'aliphatic'. By an asymptotic fitting dependencies in Fig. 5 to $n=0$, one can get a difference in the densities for $\rho_{\mathrm{I}}$ and $\rho_{\text {al }}$ by a factor greater than 2 at $293 \mathrm{~K}$. It is, therefore, qualitatively clear why an increase in the number of $\mathrm{CH}_{2}$ groups in hf-BILs leads to a decrease in density. Indeed, an increase in the fraction of less dense hydrocarbon chains should decrease the total density of the system.

The dependence of density on the number, $n$, of $\mathrm{CH}_{2}$ and $\mathrm{CH}_{3}$ groups in the long alkyl chains of cations is generally nonlinear (see Fig. 4 and 5). These dependencies appear to bend near $n=8$. Initially, an attempt was made to simulate these dependencies using a simple additive model. It was assumed that the system could be described as a sum of 'ionic' and 'aliphatic' volume fractions with densities of these fractions independent of the number of $\mathrm{CH}_{2}$ and $\mathrm{CH}_{3}$ groups in the long alkyl chains of cations. Therefore, contributions of 'ionic' and 'aliphatic' fractions were assumed to be additive. The expected density of the hf-BILs in this case may be described as (see eqn (5)):

$$
\rho=\frac{m_{\mathrm{I}}+m_{\mathrm{al}}}{V_{\mathrm{I}}+V_{\mathrm{al}}}=\frac{m_{\mathrm{I}}+n \cdot m_{\mathrm{CH}_{2}}}{V_{\mathrm{I}}+n \cdot V_{\mathrm{CH}_{2}}}
$$

Here, $n$ is the number of $\mathrm{CH}_{2}$ and $\mathrm{CH}_{3}$ groups in the long alkyl chain of pyrrolidinium cations, while $m_{\mathrm{CH}_{2}}$ and $V_{\mathrm{CH}_{2}}$ are the mass and the volume of $\mathrm{CH}_{2}$ and $\mathrm{CH}_{3}$ segments in long alkyl chains of cations. In order to use eqn (5) as an interpolation to the experimental dependence in Fig. 5, the following values were used: $m_{\mathrm{I}}=1.08 \times 10^{-21} \mathrm{~g}, \rho_{\mathrm{I}}=1.23 \mathrm{~g} \mathrm{ml}^{-1}$ (from the extrapolation in Fig. 5 to $n=0), V_{\mathrm{I}}=m_{\mathrm{I}} / \rho_{\mathrm{I}}=8.78 \times 10^{-22} \mathrm{ml}$, $m_{\mathrm{CH}_{2}}=2.33 \times 10^{-23} \mathrm{~g}$ and $V_{\mathrm{CH}_{2}}$ was used as a fitting parameter. The solid line in Fig. 5 shows the best fit, which was obtained at $V_{\mathrm{CH}_{2}}=2.58 \times 10^{-22} \mathrm{ml}$. These calculated values fit well with the experimental values. A similar procedure was performed to fit the experimental density data obtained at higher temperatures. The best results are shown in Fig. 6, where one can see that the calculations fit the experimental data rather well (see Fig. 6, bottom), because the deviation of the calculation from the experimental data is $\leq 0.005$, that is, just $\leq 0.5 \%$.

The approach using additivity of densities from different regions with constant densities is consistent with the established concept that in certain ILs the alkyl chains form a separate phase. ${ }^{20-22}$ However, separated phases of ILs may not grow to sizes much larger than the molecular size to not violate the condition of electrostatic neutrality of the bulk media. Therefore, these microscopic sub-phases should probably form a type of nano-scaled domains, with, a specific example of multilayered or sponge-like structures widely discussed in different publications on ILs.

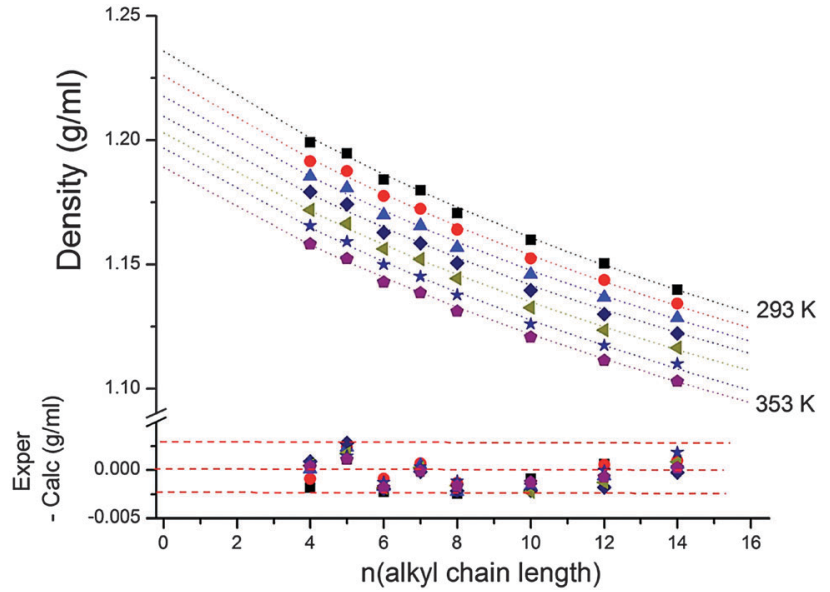

Fig. 6 Densities of studied ILs at temperatures in the range of 293-353 K as a function of the number, $n$, of $\mathrm{CH}_{2}$ and $\mathrm{CH}_{3}$ groups in the long alkyl chain of cations, $-\mathrm{C}_{n} \mathrm{H}_{2 n+1}$, and the best fit using eqn (5) with volumes of 'ionic' and 'aliphatic' of regions presented in Table 1. Deviations of experimental and calculated data are shown in the bottom of the figure.

A more complicated model was also applied in this work to make an effort to describe more precisely the experimental data presented in Fig. 4. In this model it was assumed that the density of the 'aliphatic' regions depends on the length of the long hydrocarbon chains of the cations, similar to the case of saturated hydrocarbons. ${ }^{34}$ This assumption seems reasonable, because 'aliphatic' regions have a smaller density. Thus, the density for these regions should be more sensitive to changes in the molecular structure of the components in these IL systems. An analysis of the density data based on this model may be found in the ESI $\dagger$ of this paper. In summary, it was shown that this more complicated model does not improve considerably the fit of the calculated density values with the experimental ones. Therefore, the simple 'additive' model for the density of these hf-BILs describes rather well the density dependencies of hf-BILs on the length of long alkyl chains of dialkylpyrrolidinium cations.

From this simple model, which originated from the idea of additivity of 'ionic' and 'aliphatic' region contributions, it follows that the structure (micro-structure) of the ILs can also be described well using a simple 'mosaic type' model. Indeed, this model may only be valid if these regions are separated into phases or microphases with only slight inter-phase interactions, if any.

Table 1 shows that an increase in temperature leads to almost no change in density for 'aliphatic' (as already discussed above) and to a decrease in the densities of 'ionic' regions at temperatures up to $333 \mathrm{~K}$. This means that 'ionic' regions are much more compressible than the less dense 'aliphatic' regions. Therefore, the increase in molecular mobility in 'ionic' regions results in an increase in molecular volumes and a decrease in densities. The densities in the 'aliphatic' regions, which contain long alkyl chains of cations are much larger (by a factor of $\sim 1.25$ ) than those in saturated hydrocarbons with the same chain length (see Fig. 5, open squares) and are comparable with those in highly ordered hydrophobic bilayers of saturated lipids. ${ }^{33}$ 
Table 1 Parameters of eqn (5) for best fit of experimental data in Fig. 6 and the densities of 'ionic' and 'aliphatic' regions calculated for the best fit

\begin{tabular}{lllll}
\hline$T / \mathrm{K}$ & $V_{\mathrm{I}} / 10^{-22} \mathrm{ml}$ & $V_{\mathrm{al}} / 10^{-22} \mathrm{ml}$ & $\rho_{\mathrm{I}} / \mathrm{g} \mathrm{ml}^{-1}$ & $\rho_{\mathrm{al}} / \mathrm{g} \mathrm{ml}^{-1}$ \\
\hline 293 & 87.80 & 2.57 & 1.24 & 0.908 \\
303 & 88.50 & 2.57 & 1.23 & 0.908 \\
313 & 89.10 & 2.57 & 1.22 & 0.908 \\
323 & 89.70 & 2.58 & 1.21 & 0.908 \\
333 & 90.20 & 2.60 & 1.20 & 0.907 \\
343 & 90.65 & 2.62 & 1.20 & 0.891 \\
353 & 91.25 & 2.63 & 1.19 & 0.891
\end{tabular}

This means that the long hydrocarbon chains of cations are packed very tightly in the 'aliphatic' regions. A comparison of these values $\left(0.891-0.908 \mathrm{~g} \mathrm{ml}^{-1}\right.$ ) and the densities of saturated hydrocarbons at high pressures ${ }^{34}$ shows that the density of $\mathrm{CH}_{2}$ regions in hf-BILs is larger than that of $n$-decane at $190 \mathrm{MPa}$ (ca. $1875 \mathrm{~atm})$ and $298 \mathrm{~K}\left(0.82 \mathrm{~g} \mathrm{ml}^{-1}\right)$ and are comparable to the density of a paraffin wax under normal conditions $\left(0.9 \mathrm{~g} \mathrm{ml}^{-1}\right)$. The very tight packing of alkyl chains in ILs is also confirmed by the minor dependence of their densities on temperature (see Table 1, right column). In the temperature range of 293-333 K, $\rho_{\mathrm{al}}$ does not change and it slightly decreases only at temperatures of $333-353 \mathrm{~K}$.

\section{Discussion}

According to the modern point of view, any substance composed of anions and cations must possess some kind of short-range organisation to fulfil local electro-neutrality conditions. ${ }^{35}$ In the case of ILs, such short-range ordering does not lead to longrange structures, but might lead to nano-segregated fluids. ${ }^{35,36}$ If the IL has to order its high-charge density components into local structures, then the low-charge density components (not participating in those structures) must be segregated elsewhere. This can lead to formation of the two types of regions (mediumrange nano-scale domains), a high-charge density (polar) network permeated by low-charge density (non-polar) regions.

Our results show that hf-BILs may spontaneously separate into two liquid sub-phases with different diffusion coefficients. Because the separation occurs only for sufficiently large hydrophobic cations, evidently, the driving forces of this separation are both electrostatic and so called 'hydrophobic' interactions. Recently, similar splitting of $D$ s has been observed in another $\mathrm{IL},\left[\mathrm{P}_{6,6,6,14}\right][\mathrm{BMB}]$, in which the temperature dependencies of two diffusion components ('fast-diffusing' and 'slow-diffusing') were also obtained. ${ }^{19}$ The values of $D \mathrm{~s}$ in the corresponding sub-phases of $\left[\mathrm{P}_{6,6,6,14}\right][\mathrm{BMB}]^{19}$ and $\left[\mathrm{C}_{n} \mathrm{C}_{1}\right.$ Pyrr $][\mathrm{BMB}]$ hf-BILs, studied here, are very close, supporting the idea of a common mechanism of microphase separation (hydrophobic interaction) in both cases.

The alkyl chain length dependence, which was reported for sub-phase separation in ILs, has been theoretically described by Shimizu et al. ${ }^{35}$ When alkyl-side chains are short $\left(\mathrm{C}_{2}-\mathrm{C}_{4}\right)$, the non-polar domains consist of hydrocarbon-like "islands" in the center of a continuous polar network, whereas for longer alkyl side chains those islands start to connect, forming a second continuous micro-phase, thus establishing a bi-continuous segregated phase. Later, in an experimental study of volatility of ILs in a homologous series of 1-alkyl-3-methylimidazolium bis(trifluoromethylsulfonyl)imide, [ $\left.\mathrm{C}_{n} \operatorname{mim}\right]\left[\mathrm{Ntf}_{2}\right]$, with $n=2-12$, Rocha et $a l .{ }^{36}$ have found a 'percolation limit' at around $n=6$, at which contribution of hydrophobic interactions became comparable with the electrostatic interaction between ions in these ILs. The effect of a similar type of separation into two subphases with different $D$ s was observed experimentally on hf-BIL diffusion in this study (Fig. 2). ${ }^{1} \mathrm{H}$ NMR spectra of fractional diffusion components in sub-phases showed that the 'fast-diffusing' component (red line in Fig. 3) has a more intense NMR signal at chemical shifts of aromatic protons, while in the 'slowdiffusing' component (blue line in Fig. 3) the intensity of the resonance line assigned to aromatic protons is considerably smaller. In pyrrolidinium-BMB hf-BILs, both cations and anions have aliphatic protons, but only BMB anions have aromatic protons. Therefore, here, similar to $\left[\mathrm{P}_{6,6,6,14}\right][\mathrm{BMB}],{ }^{19}$ the 'slow diffusing' component may predominantly be due to the cations, while the 'fast-diffusing' component may predominantly be due to the anions (Fig. 1).

Self-diffusion under conditions of micro-phase separation is different from that for a bulk liquid. Indeed, in systems with a phase separation on the molecular levels, molecules (or ions) collide with phase boundaries. Moreover, long-scale diffusion in curvilinear trajectories in different phases will additionally decrease experimentally measured diffusion coefficients, which may be smaller than the corresponding molecular diffusion coefficients. Some differences in the micro-phase structures of our samples, $\left[\mathrm{C}_{10} \mathrm{C}_{1} \mathrm{Pyrr}\right][\mathrm{BMB}]$ and $\left[\mathrm{C}_{14} \mathrm{C}_{1} \mathrm{Pyrr}\right][\mathrm{BMB}]$, may account for the difference in values of the 'fast diffusing' $D \mathrm{~s}$, corresponding to the BMB anion. Applying Einstein's equation for mean-squared displacements (eqn (6)):

$$
\left\langle r^{2}\right\rangle=6 \cdot D \cdot t_{\mathrm{d}}
$$

with measured $D$ s for cations and anions, one can acquire displacements for cations in the range from $0.4 \mu \mathrm{m}$ (at lower temperatures) to $1.9 \mu \mathrm{m}$ (at higher temperatures), and for anions such displacements will be around $2.4 \mu \mathrm{m}$. Evidently, smaller displacements have less effect on the apparent Ds. Therefore, $D$ s of cations are disturbed less by the internal micro-phase structure than the $D$ s of anions.

In studies of the relationship between structures of cations and anions, and their physicochemical properties in the homologous series of $\left[\mathrm{C}_{n} \mathrm{mim}\right]\left[\mathrm{Ntf}_{2}\right]$, it has been shown that density dependencies of these ILs on the alkyl chain length, among other physical properties such as viscosity and conductivity, are strongly correlated with the molecular structure of these ILs. ${ }^{35,36}$ A group contribution method for prediction of the density of ILs over a wide range of temperature and pressure has been proposed by Paduszynski and Domanska. ${ }^{22}$ Lazzus distinguished 92 functional groups contributing additively to the molar volume of ILs. ${ }^{25}$ In the latter study, cations were modelled as ionic moieties consisting of the cation core and a number of alkyl chains and/or functional groups attached to the core, while anions were treated as separate ionic moieties. Slattery et $a l^{21}$ have 
suggested that the molar volume $V_{\mathrm{m}}$ of ILs can be considered as the sum of individual contributions of cations and anions. It has been shown experimentally that $V_{\mathrm{m}}$ increases linearly with the number of the $\mathrm{CH}_{2}$ units in the alkyl chain attached to the cation. Following the observation of Rebelo et al. ${ }^{20}$ the effective molar volume was assigned to the methylimidazolium core and the $\mathrm{CH}_{2}$ groups. Machanová et al. have studied densities of $\left[\mathrm{N}_{n 222}\right]\left[\mathrm{Ntf}_{2}\right]$ ILs (with $n=6-14$ ) at the atmospheric pressure as a function of the length of one of alkyl chains of the cation, as well as temperature. $^{23}$ These authors have suggested that the molar volume of cations varies as a quadratic function of $T .^{23}$ Therefore, additive density models, which suggested linear and non-linear contributions of different chemical groups present in ions to the molar volume, are not rare. Our model originates from both density and diffusion dependencies on the alkyl chain length of the pyrrolidinium cations. The model is different from all previously reported models, because it suggests that the molar volume is not a sum of individual contributions from ions, but the sum of the partial long chain volume of cations ('aliphatic' regions) and volumes of anions and the residual part, i.e. without the long alkyl chain, of cations ('ionic' regions). This approach seems to be reasonable, because long chains of cations may form separate hydrophobic microscopic liquid sub-phases governed by van der Waals inter-chain interactions. ${ }^{23,36}$

One of basic approaches to describe diffusion processes is the theory of free volume, which was first proposed by Cohen and Turnbull more than 50 years ago. ${ }^{32}$ This theory considers a particle performing a random walk, while each elementary step of this process is limited by the occurrence of a free volume, $v_{\mathrm{f}}$, greater than a critical size, $v^{*}$, next to the diffusing particle. The equation for the diffusion coefficient with a free volume can be written in the form (see eqn (7)):

$$
D=D^{*} \cdot \exp \left(-\gamma \frac{v^{*}}{v_{\mathrm{f}}}\right)
$$

where $D^{*}$ is a constant and $\gamma$ is a factor to correct for overlapping free volumes $(0.5-1)$. The usual approximation for $v^{*}$ is the van der Waals volume per molecule, which can be estimated as (eqn (8)):

$$
v_{\mathrm{f}}=v_{\mathrm{av}}-v^{*}
$$

where $v_{\mathrm{av}}$ is the average volume of the molecule. The free volume is formed near the molecule/ion, therefore, for molecules/ ions composed of a number of diverse chemical groups, the total free volume is a sum of free volumes neighbouring the particular chemical groups. In our particular case of dialkylpyrrolidinium cations the following equation can be written (eqn (9)):

$$
v_{\mathrm{f}}(\text { cation })=v_{\mathrm{f}}(\text { methyl-pyrrolidinium core })+v_{\mathrm{f}}\left(n \mathrm{CH}_{2}\right)
$$

The density analysis of hf-BILs showed (see Table 1) that the density of 'aliphatic' regions of $\mathrm{CH}_{2}$ groups under normal conditions is extremely high, and comparable to that of saturated hydrocarbons at extremely high pressures, due to chemical bonding of the alkyl chains with the methyl-pyrrolidinium cation core. The exact mechanism, by which the cation cores may 'compress' the 'aliphatic' regions is not yet clear. The primary process might cause a decrease in the mobility of the alkyl chains by the bound pyrrolidinium core or, more likely, the pressure due to electrostatic forces between the cations and anions. ${ }^{35}$ Note that the density of a neutral liquid, n-methyl-pyrrolidine, is only $0.819 \mathrm{~g} \mathrm{ml}^{-1}$ at $298 \mathrm{~K}$. Therefore, electrostatic interactions between pyrrolidinium cations and $\mathrm{BMB}$ anions contribute considerably to the packing of ions in these hf-BILs, so that densities of $\left[\mathrm{C}_{n} \mathrm{C}_{1}\right.$ Pyrr $][\mathrm{BMB}]$ ionic liquids are larger than $1 \mathrm{~g} \mathrm{ml}^{-1}$ in the whole temperature interval and for all ionic liquids in this study and approaching $1.24 \mathrm{~g} \mathrm{ml}^{-1}$ for $n=0$.

Considering that the effect of the free volume on regions of long cation alkyl chains is infinitesimal, eqn (9) turns into the following relation (see eqn (10)):

$$
v_{\mathrm{f}}(\text { cation })=v_{\mathrm{f}}(\text { methyl-pyrrolidinium core }) \text {. }
$$

It is, therefore, evident why the Ds of the "slow-diffusing", component are not influenced by the number of $\mathrm{CH}_{2}$ groups in the long alkyl chain of cations: $n$ does not influence the free volume of the dialkylpyrrolidinium cation.

Tight packing of alkyl cation chains may lead to ordering of long cation chains in the studied hf-BILs in the manner of a liquid crystal. Simulations showed that, when cationic chains are adequately long, they tend to become parallel to each other and generate liquid crystal-like layers. ${ }^{37}$ More experiments are needed to confirm this idea.

\section{Conclusion}

${ }^{1} \mathrm{H}$ diffusion NMR demonstrated that hf-BILs with the structure $\left[\mathrm{C}_{n} \mathrm{C}_{1} \mathrm{Pyrr}\right][\mathrm{BMB}]$ are rather complex systems in molecular organisation and diffusion. For $n=4-8$, in the entire temperature range of study, these hf-BILs show single-component diffusion decays with almost equal diffusion coefficients. For $n=10$ and 14, the NMR results demonstrate the presence of two diffusion coefficients, which differ by almost two orders of magnitude and correspond to the two liquid sub-phases. The driving forces of this separation are both electrostatic interactions between cations and anions and the hydrophobic interaction between long alkyl chains of cations. The dependence of hf-BIL density on the number of $\mathrm{CH}_{2}$ groups in the long chain of cations can be described well using a simple additive model, in which 'ionic' and 'aliphatic' regions make additive contributions. The densities in 'aliphatic' regions are comparable to those of saturated hydrocarbons at extremely high pressures ( $>1850 \mathrm{~atm})$, evidently because of strong intermolecular electrostatic interactions in the system. This leads to an infinitesimal free volume of the long alkyl chains of the cations and independence of diffusion ("slowdiffusing" component) in the cation-containing phase on the number of $\mathrm{CH}_{2}$ groups in the long alkyl chains of the cations.

\section{Acknowledgements}

The Knut and Alice Wallenberg Foundation and the Swedish Research Council are gratefully acknowledged for supporting this work. The Foundation in memory of J. C. and Seth M. Kempe is 
gratefully acknowledged for financial support (grants for NMR equipment at LTU and for chemicals). The linguistics services of Kazan Federal University and "Scriptia Academic Editing" are acknowledged for proof-reading of this manuscript.

\section{References}

1 T. Torimoto, T. Tsuda, K. Okazaki and S. Kuwabata, Adv. Mater., 2010, 22, 1196.

2 E. Binetti, A. Panniello, L. Triggiani, R. Tommasi, A. Agostiano, M. L. Curri and M. Striccoli, J. Phys. Chem. B, 2012, 116, 3512.

3 W. Xu, L. M. Wang, R. A. Nieman and C. A. Angell, J. Phys. Chem. B, 2003, 107, 11749.

4 J. P. Paraknowitsch, A. Thomas and M. Antonietti, J. Mater. Chem., 2010, 20, 6746.

5 H. Xiang, B. Yin, H. Wang, H. Lin, X. Ge, S. Xie and C. Chen, Electrochim. Acta, 2010, 55, 5204.

6 H. Tokuda, K. Hayamizu, K. Ishii, M. A. B. H. Susan and M. Watanabe, J. Phys. Chem. B, 2005, 109, 6103.

7 F. U. Shah, S. Glavatskih, D. R. MacFarlane, A. Somers, M. Forsyth and O. N. Antzutkin, Phys. Chem. Chem. Phys., 2011, 13, 12865.

8 F. U. Shah, S. Glavatskih and O. N. Antzutkin, Tribol. Lett., 2013, 51, 281-301.

9 X. Sun, H. Luo and S. Dai, Talanta, 2012, 90, 132.

10 F. U. Shah, S. Glavatskih, P. M. Dean, D. R. MacFarlane, M. Forsyth and O. N. Antzutkin, J. Mater. Chem., 2012, 22, 6928-6938.

11 R. Atkin and G. G. Warr, J. Phys. Chem. C, 2007, 111, 5162.

12 S. Zhang, X. Li, H. Chen, J. Wang, J. Zhang and M. Zhang, J. Chem. Eng. Data, 2004, 49, 760.

13 G. Annat, D. R. MacFarlane and M. Forsyth, J. Phys. Chem. B, 2007, 111, 9018.

14 G. L. Burrell, I. M. Burgar, Q. Gong, N. F. Dunlop and F. Separovic, J. Phys. Chem. B, 2010, 114, 11436.

15 K. Hayamizu, S. Tsuzuki, S. Seki and Y. Umebayashi, J. Chem. Phys., 2011, 135, 084505.

16 T. G. A. Youngs, J. D. Holbrey, C. L. Mullan, S. E. Norman, M. C. Lagunas, C. D’Agostino, M. D. Mantle, L. F. Gladden, D. T. Bowron and C. Hardacre, Chem. Sci., 2011, 2, 1594.

17 A. E. Frise, T. Ichikawa, M. Yoshio, H. Ohno, S. V. Dvinskikh, T. Kato and I. Furo, Chem. Commun., 2010, 46, 728.
18 K. Hayamizu, S. Tsuzuki, S. Seki and Y. Umebayashi, J. Phys. Chem. B, 2012, 116, 11284.

19 A. Filippov, F. U. Shah, M. Taher, S. Glavatskih and O. N. Antzutkin, Phys. Chem. Chem. Phys., 2013, 15, 9281.

20 L. P. N. Rebelo, J. N. C. Lopes, J. M. S. S. Esperanca, H. J. R. Guedes, J. Lachwa, V. Najdanovic-Visak and Z. P. Visak, Acc. Chem. Res., 2007, 40, 1114.

21 J. Slattery, C. Daguenet, P. Dyson, T. Schubert and I. Krossing, Angew. Chem., Int. Ed., 2007, 46, 5384.

22 K. Paduszynski and U. Domanska, Ind. Eng. Chem. Res., 2012, 51, 591.

23 K. Machanová, A. Boisset, Z. Sedláková, M. Anouti, M. Bendová and J. Jacquemin, J. Chem. Eng. Data, 2012, 57, 2227.

24 P. Kilaru, G. A. Baker and P. Scovazzo, J. Chem. Eng. Data, 2007, 52, 2306.

25 J. Lazzus, Chem. Eng. Commun., 2010, 197, 974.

26 M. Taher, F. U. Shah, A. Filippov, P. de Baets, S. Glavatskih and O. N. Antzutkin, RSC Adv., 2014, 4, 30617.

27 Y. L. Wang, F. U. Shah, S. Glavatskih, O. N. Antzutkin and A. Laaksonen, J. Phys. Chem. B, 2014, 118, 8711.

28 R. Gusain, R. Singh, K. L. N. Sivakumar and O. P. Khatri, $R S C A d v .$, 2014, 4, 1293.

29 S. Yu, S. Lindeman and C. D. Tran, J. Org. Chem., 2008, 73, 2576-2591.

30 E. O. Stejskal and J. Tanner, J. Chem. Phys., 1965, 42, 288.

31 P. Stilbs, K. Paulsen and P. C. Griffiths, J. Phys. Chem., 1996, 100, 8180.

32 M. Cohen and D. Turnbull, J. Chem. Phys., 1959, 31, 1164.

33 A. Filippov, B. Munavirov, G. Gröbner and M. Rudakova, Magn. Reson. Imaging, 2012, 30, 413.

34 K. Liu, Y. Wu, M. A. McHugh, H. Baled, R. M. Enick and B. D. Morreale, J. Supercrit. Fluids, 2010, 55, 701.

35 K. Shimizu, M. F. C. Gomes, A. A. H. Padua, L. P. N. Rebelo and J. N. C. Lopes, J. Mol. Struct., 2010, 946, 70.

36 M. A. A. Rocha, C. F. R. A. C. Lima, L. R. Gomes, B. Schröder, J. A. P. Coutinho, I. M. Marrucho, J. M. S. S. Esperanca, L. P. N. Rebelo, K. Shimizu, J. C. Lopes and L. M. N. B. F. Santos, J. Phys. Chem. B, 2011, 115, 10919.

37 Y. Ji, R. Shi, Y. Wang and G. Saielli, J. Phys. Chem. B, 2013, 117, 1104. 